\title{
Zero tolerance to trans fatty acids in infant formula? Fears, fiction, and facts
}

\author{
Alex TL Siu *, Anthony WK Ng, MRCP, FHKAM (Paediatrics), Charles YC Wong, MD, FRCP \\ Department of Paediatrics, Tsuen Wan Adventist Hospital, Tsuen Wan, Hong Kong
}

Hong Kong Med J 2014;20:79-81

*charx.siu@gmail.com

DOI: 10.12809/hkmj134123

Despite counselling that breast is best, a new mother elects to bottle feed at the hospital's newborn nursery:

Mother: Is the newborn formula that the hospital is providing safe?

Doctor: This is one of several that are rotating through. Hong Kong Government had tested and found them safe. ${ }^{1}$

Mother: So it contains no harmful substance like trans fatty acids (tFA)?

Doctor: It has $t F A$, but in miniscule quantity, well within acceptable limits.

Mother: But my baby will be fed 6 times a day for months, each feed containing a very small amount of harmful $t F A$... Is that good?

Do our frontline health care workers know enough about the effects of tFA in infant formula to properly advise clients? Is this mother's fear of miniscule amounts of tFA in newborn infant formula justified? When the formula label lists tFA content as zero, is this the whole truth and not just fiction? This article briefly presents the essential facts.

On 8 July 2013, the South China Morning Post (SCMP) published its own commissioned investigation carried out by an independent laboratory on the tFA content of several Mainland China baby formula brands. ${ }^{2}$ Although the product labels stated zero tFA content, 0.4-0.6 g of tFA was found in the serving size of several brands. China follows the Codex Alimentarius Commission guidelines on tFA-free labelling, limiting to $<3 \%$ of total fat content, a boundary not breached by any of those investigated. In response, official Chinese government press agency Xinhuanet published an editorial accusing the SCMP of demonising Mainland Chinese formula, preying on the public's lack of understanding regarding tFA. ${ }^{3}$

Adding to this controversy, one brand of formula sold in Hong Kong recently notified local hospital nurseries that its newborn formulation will change from $0 \mathrm{~g}$ to $0.014 \mathrm{~g}$ tFA per serving size. ${ }^{4}$ Currently there are no specific requirements for nutritional composition of infant formulas in Hong Kong-only recently, has a legislative proposal been drafted to follow codex guidelines for food intended for infants under 36 months of age. ${ }^{5}$ Whilst this apparently increased amount of tFA per feed remains minute, protracted intake in our newborns from multiple daily feedings is a prima facie indication for further evaluation. It is the onus of each individual to manage their nutritional intake; the same cannot be applied to newborns.

Trans fatty acids are a type of unsaturated fatty acid, in which the carbon double bond is in the trans-isomer configuration. Developed in the early 1900s, tFA bridge the gap between solid and liquid lipid products. ${ }^{6}$ Fully hydrogenated, saturated fatty acid chain molecules line up in an orderly fashion and maximise intermolecular forces, producing solid fats. Trans fatty acids which are partially hydrogenated, unsaturated fatty acids, have kinks in the molecular tails, preventing stable interactions. This property allows margarine, comprised mainly of tFA, to be semi-solid, and spreadable right out of the refrigerator. Production is cheaper compared to other semi-solid oils, and partially hydrogenated oils extend their shelf life, making them a popular choice for processed food manufacturing.

Studies have shown an inverse correlation between tFA consumption and good health. While both saturated and unsaturated fats have the negative effect of increasing low-density lipoprotein cholesterol levels, tFA have the additional adverse effect of lowering 'good' high-density lipoprotein levels. ${ }^{7}$ The alleged health hazard is an increased risk of atherosclerotic coronary heart disease, which is said to double with every $2 \%$ caloric increase of tFA consumption instead of carbohydrates; the equivalent effect is matched by saturated fats with a $15 \%$ increase. ${ }^{8}$ Although the exact biochemical mechanism has not been fully elucidated in human studies, mouse studies suggest that this may be due to suppression of the response to transforming growth factor $-\beta$ in the vascular endothelium. ${ }^{9}$

Trans fatty acids are found naturally in bovine milk, due to natural hydrogenation reactions in ruminant physiology. While the Codex Alimentarius prohibits the use of commercially hydrogenated oils in infant formulas, milk fat is often used in formula production; for this reason, there is an acceptable tolerance of $<3 \%$ tFA composition. ${ }^{10}$ Human breast milk also contains tFA in low levels, which vary according to the mother's diet; breastfeeding mothers are advised to be aware of and reduce 
TABLE. The regulation type and details of trans fatty acids (tFA) in several countries ${ }^{13-17}$

\begin{tabular}{lcc}
\hline Country & Type of regulation & \multicolumn{1}{c}{ Implementation in chronological order } \\
\hline Denmark & Legal restriction & $2003-$ tFA content shall not $>2 \%$ of total oil or fat \\
\hline United States (Federal) & Labelling & $2003-$ tFA levels of $<0.5 \mathrm{~g} /$ serving may be labelled as $0 \mathrm{~g}$ \\
\hline Switzerland & Legal restriction & $2008-$ tFA content shall not $>2 \%$ of total oil or fat ${ }^{13}$ \\
\hline Canada (Federal) & Labelling & $2005-$ tFA levels of $<0.2 \mathrm{~g} /$ serving may be labelled as $0 \mathrm{~g}$ \\
\hline California, US (State) & Legal restriction & 2008 - All restaurants prohibited from using tFA in food \\
\hline Hong Kong SAR & Labelling & 2008 - tFA levels of $<0.3 \mathrm{~g} / 100 \mathrm{~g}$ of food may be labelled as $0 \mathrm{~g}^{14}$ \\
\hline BC, Canada (Provincial) & Legal restriction & $2009-$ tFA content shall not $>5 \%$ of total fat ${ }^{15}$ \\
\hline United Kingdom & Voluntary pledge & 2012 - Voluntary pledges by individual corporations to eliminate artificial tFA from production ${ }^{16}$ \\
\hline Mainland PRC & Labelling & $2013-$ tFA levels of $<0.3 \mathrm{~g} / 100 \mathrm{~g}$ of food may be labelled as $0 \mathrm{~g}^{17}$ \\
\hline
\end{tabular}

dietary tFA intake for the health of both the parent and the child. ${ }^{11}$

In 2003, the World Health Organization recommended that tFA should be limited to less than $1 \%$ of daily caloric intake. ${ }^{12}$ As shown in the Table, ${ }^{13-17}$ many developed countries have since implemented new nutritional regulations in attempts to cull the harmful effects of tFA on society. Since 2003, Denmark has banned the use of industrially produced tFA in food products. ${ }^{18}$ By 2006, Canada and the United States had mandated labelling of foods with more than $0.2 \mathrm{~g}$ and $0.5 \mathrm{~g}$ of tFA content per serving, respectively. ${ }^{19,20}$ In 2008, California banned all restaurants from cooking with tFA. ${ }^{21}$

Evidently, tFA provide no known benefit to human health. ${ }^{22}$ At the time of writing of this article, the Hong Kong SAR Government (HKG) had no regulations to restrict tFA levels in food ${ }^{23}$-there are only policies regarding nutritional labelling, and guidelines advising the public to reduce consumption. $^{24}$ Hong Kong Consumer Council has published multiple articles in its $\mathrm{CHOICE}$ magazine, alerting the public on this health issue and investigating tFA levels in local delicacies such as egg tarts, buns, and swiss roll cakes. ${ }^{25-28}$ With all this literature directed at tFA, it is surprising the HKG has yet to legislate content level restrictions.

Frontline doctors are duty-bound to advise parents on details such as tFA content in baby formula and the consequence of its intake. Only adequate information can hope to enable patients to have true autonomy of choice. In addition to being encouraged to breastfeed their newborns, all mothers should be encouraged to limit their own personal intake of tFA. Hong Kong Consumer Council advises the public to reduce tFA consumption by checking nutrition labels and choose food with less tFA (eg no margarine, shortening, etc), and use less butter and lard to cook. The HKG should aim to follow the example of Denmark. They start off by informing the public and call for a public debate on the issue. Then lead up to proposing and implementing legislation to limit tFA in infant diets down to near-zero levels. As always, new mothers should be provided with appropriate information: "breast is best", but should formula feeding remain the mother's choice, accurate and credible information on the potential consequences of such choices should also be provided.

\section{References}

1. Family Health Service, Department of Health, Hong Kong. Infant feeding (Newborn to six months old). Available from: http://www.fhs.gov.hk/english/health_info/files/n_2. pdf. Accessed Jul 2013.

2. Tsang E, Wei L, Sun C. Trans-fat found in mainland China milk formula brands. Available from: http://www.scmp. com/news/hong-kong/article/1277600/trans-fat-foundmainland-china-baby-milk-formula-brands. Accessed 28 Jul 2013.

3. An attempt to demonize infant formulas regarding trans fatty acids? [in Chinese]. Available from: http://news. xinhuanet.com/food/2013-07/09/c_124982552.htm. Accessed 28 Jul 2013.

4. Information sheet regarding new formula nutritional breakdown [hardcopy letter to a private hospital nursery]. Abbott Laboratories Limited; Jul 2013.

5. Legislative proposals relating to formula products and foods intended for infants and young children under the age of 36 months in Hong Kong. Hong Kong: Centre for Food Safety; 2012.

6. Martin CA, Milinsk MC, Visentainer JV, Matsushita M, deSouza NE. Trans fatty acid-forming processes in foods: a review. An Acad Bras Cienc 2007;79:343-50.

7. Brouwer IA, Wanders AJ, Katan MB. Effect of animal and industrial trans fatty acids on HDL and LDL cholesterol levels in humans-a quantitative review. PLoS One 2010;5:e9434.

8. Hu FB, Stampfer MJ, Manson JE et al. Dietary fat intake and the risk of coronary heart disease in women. $\mathrm{N}$ Engl J Med 1997;337:1491-9.

9. Chen C, Tetri L, Neuschwander-Tetri B, et al. A mechanism by which dietary trans fats cause atherosclerosis. J Nutr Biochem 2011;22:649-55.

10. ISSFAL. Dietary fats in infant nutrition. Final statement. Kansas City: International Society for the Study of Fatty Acids and Lipid Board; 2008.

11. Berger A, Fleith M, Crozier G. Nutritional implications 
of replacing bovine milk fat with vegetable oil in Infant Formulas. J Pediatr Gastroenterol Nutr 2000;30:115-30.

12. Diet, nutrition and the prevention of chronic diseases: report of a joint WHO/FAO expert consultation. WHO Technical Report Series No. 916. Geneva: WHO; 2003.

13. International Service of the Swiss Broadcasting Corporation. Swiss limit unhealthy trans fats. Available from: http://www.swissinfo.ch/eng/Home/Archive/Swiss_ limit_unhealthy_trans_fats.html?cid=6775852. Accessed $28 \mathrm{Jul} 2013$.

14. Center for Food Safety, Hong Kong. Food and Drugs (composition and labelling) regulations. Available from: http://www.cfs.gov.hk/english/food_leg/food_leg_ cl.html\#R4B. Accessed 28 Jul 2013.

15. Ministry of Healthy Living and Sport, Canada. Province restricts trans fat in B.C. Available from: http://www2.news.gov.bc.ca/news_releases_20052009/2009HLS0013-000315.htm. Accessed 28 Jul 2013.

16. McClenaghan M. Analysis: unhealthy friendships with Department of Health. Available from: http:// www.thebureauinvestigates.com/2011/11/25/analysisunhealthy-friendships-with-department-of-health. Accessed 28 Jul 2013.

17. National standard for trans fat labeling. Available from: http://www.china.org.cn/china/2011-11/04/content 23820814.htm. Accessed 28 Jul 2013.

18. Stender S, Dyerberg J, Bysted A, Leth T, Astrup A. A trans world journey. Atheroscler Suppl 2006;7:47-52.

19. Information letter: labelling of trans fatty acids. Available from: http://www.inspection.gc.ca/english/fssa/labeti/ inform/transe.shtml. Accessed 28 Jul 2013.

20. Misko G. FDA requires trans fatty acid labeling for foods and dietary supplements. Food \& Drug Packaging; 2003.

21. California State Assembly. Assembly Bill No. 97. 2008-0725.

22. Food and nutrition board, institute of medicine of the national academies. Dietary reference intakes for energy, carbohydrate, fiber, fat, fatty acids, cholesterol, protein, and amino acids (macronutrients). Washington, DC: National Academies Press; 2005: 423.

23. Centre for Food Safety, Hong Kong. Food Laws in Hong Kong. Available from: http://www.cfs.gov.hk/english/ food_leg/food_leg.html. Accessed 28 Jul 2013.

24. Healthy eating. Available from: http://www.gov.hk/en/ residents/health/foodsafe/healthyeating.htm. Accessed 28 Jul 2013.

25. Consumer Council. [Trans Fats]. 麵包餅乾或含有害「反 式脂肪」. CHOICE 2007 \#364

26. Consumer Council. [Watch out for trans fats and saturated fats in your daily meals]. 揭露含反式脂肪的熱門食品. CHOICE 2007 \#372.

27. Consumer Council. [Beware of the trans fats in your doughnut, wife cake and cream wafer]. 81款熱賣食品含 反式脂肪 小心選擇冬甩/老婆餅/威化餅. CHOICE 2008 \#379.

28. Trans fatty acids in local foods. Available from: http:// www.cfs.gov.hk/english/programme/programme_rafs/ programme_rafs_n_01_15.html. Accessed 28 Jul 2013.

\section{Answers to CME Programme Hong Kong Medical Journal December 2013 issue}

Hong Kong Med J 2013;19:531-8

I. Perioperative antithrombotic management in joint replacement surgeries
A
1. True
2. True
3. False
4. False
5. False
B
1. True
2. True
3. True
4. False
5. False

Hong Kong Med J 2013;19:556-9

II. Oculopharyngeal muscular dystrophy: underdiagnosed disease in Hong Kong
A
1. True
2. False
3. False
4. True
5. True
B
1. True
2. True
3. True
4. False
5. True 